\title{
La disputa de los siglos
}

Quietud matinal, Dos seres discurren por el parque. Uno es el viejo Goethe, crguido el torso apolineo, viva la mirada, tranquilo el ademán. $\mathrm{El}$ otro un cuerpo tricéfalo, desarticulado, en el que asoman las testas de Apollinaire, Marinetti, Picasso, triple manifestación del genio mosaico de vanguardia. El nórdico expresa, altanero, el frío radiar del alma clásica. Las tres cabezas latinas giran al esplendor del vanguardismo.

\section{GOETHE}

La mayor desgracia de este tiempo que nada deja madurar, es que se devora en cada instante el instante anterior, derrochando el día en el día, viviendo siempre del momento, sin poner nada en pie. Todo vuela de casa en casa, de ciudad en ciudad, de país en pais, de continente en continente. ¡Es el siglo de la velocidad! ¿No se advierte que riqueza y velocidad son factores de lo mediocre? El materialismo desprecia los valores humanos en favor de las cosas, concediendo primacía al continente sobre el contenido. Cuanto más años gana, la humanidad se aleja mayormente de la aspiración a perdurar, clima natural del espíritu. Nadie piensa en lo eterno, sino en la vana fruición de lo inmediato.

\section{A pollinaire-Marinetti-Picasso}

No existe lo eterno; el tiempo todo lo destruye. Tanto da trabajar para un día o para un siglo. 
Goethe

¡Ningún sér puede caer en la nada! La vida es eterna e inquebrantables leyes protegen los tesoros vivos que el universo crea.

\section{Apollinatre-Marinetti-Picasso}

¡Frases!. . . Nada subsiste.... ¿Quiẻn lee a Píndaro? Nadie conoce verdaderamente la Commedia del Dante. Los lienzos de Zurbarán duermen en los museos. Scarlatti es para melómanos. Donatello mora en recintos cerrados. La vanguardia, en cambio, vuelve a educar los sentidos liberándolos del estatismo clásico. Somos dichosos porque somos dinámicos.

Goethe.

El arte es largo; la vida breve; el juicio lento; la ocasión huidiza. No es lícito llamar movimiento al desenfreno y fuerza a la disipación. El que termina en un instante, se priva de la fecundidad morosa del trabajo. Dinámico no es quien más se mueve, sino el que realiza con sentido.

\section{A pollinatre-Marinettri-Picasso}

Rechazamos el sistema; el único sistema aceptable es carecer totalmente de principios. 'Lo que vale es la intensidad del instante, no los resultados. Nos ignora el clásico, porque donde él concluye nosotros comenzamos.

\section{Gotthe}

Evitar la dispersión y concentrar las fuerzas. Huir de lo incoherente y superfluo para describir lo particular y profundo; he ahí la vida propia del arte. 
Apollinaire-Marinetti-Picasso

La vida del arte no es in conjunto de sistemas o reglas fijas que traban la creatividad, sino el espacio libre de obstáculos, la plenitud informe de lo no estatuído; la aceptación de todo, incluso del absurdo, cuando el absurdo responde a una actitud.

Goethe.

Una actitud... Exacto. El modernismo es actitud, desde la vacuidad interna a la pirueta expresiva.

\section{A pollinaire-Marinetti-Picasso}

También la actitud es un acto de ordenación espiritual: ¿ Por qué desdeñarla? Muchas veces el gesto es más que su potencial. Abandonando la tradición se gana la actitud pura, es decir, un nuevo modo de interpretar el mundo.

GoETHE

Dejad en paz la tradición, cuyo magno poder desconocéis: A pollinaire-Marinetti-Picasso

La tradición es el peor de los caminos; conduce a la imitación y niega la personalidad.

\section{GoEthe}

El afán del trato con los grandes predecesores es característico de los hombres eminentes. La barbarie consiste en negar el pasado. ¿Existiría Roma sin Atenas? ¿Beethoven sin Bach? $¿ E 1$ teatro shakespereano sin su antecedente la tragedia griega? La historia de la humanidad es la historia de un solo hombre; proteiforme, cambiante, que muda de apariencias, jamás en lo fundamental. Ese hombre es- tanto más sabio, tanto más ad- 
mirable, cuanto mejor se apoya en las formas que le precedieron. El "Fausto", colocado por el tiempo en la cima del pensar occidental, viene de la Grecia y de la India; del Medioevo y del Renacimiento; anuncia el barroco y preconiza el agonismo crítico de estos días. No habría existido por la sola actitud, pues la naturaleza humana no la expresa un solo hombre-individuo, por una sola experiencia, sino el pensamiento invisible y múltiple que forja la tradición y se apoya en miles de experiencias; es el esfuerzo conjunto y solidario de muchos cerebros que piensan para varias épocas.

\section{A POLlinaire-MarinetTit-Picasso}

Recordar... Recordar... Queremos la libertad física del sér enteramente libre. Rechazamos el crecer de la pirámide que impide el vuelo creador.

\section{GoETHE}

Por la memoria el hombre acumula, posee. y aprovecha su pasado. No hay un primer individuo; vivimos sobre cierta prominencia de pretérito amontonado. Esa es nuestra gloria, nuestro privilegio: una larguísima experiencia destilada poco a poco en milenios. Por eso el filósofo define al hombre superior como el sér de más larga memoria. Romper la continuidad con el pasado es querer comenzar todo de nuevo, copiando al orangután que cada dia inicia su vida mental sin relación con el ayer.

\section{Apollinaire-Marinetti-Picasso}

iQuémense las bibliotecas, destrúyanse los templos, socávense los cimientos de ciudades venerables! El "Fausto" es una horrible catedral del pensamiento, compuesta por millares de fragmentos, como el templo gótico, que no es dable contemplar sin fatiga. Es el fin de la tradición, la última "summa" del hutmanismo occidental. Para comprenderlo hay que dominar el 
panorama agobiador de todas las culturas; impregnarse de crueles filosofías; absorber estéticas contradictorias. No expresa el alma del hombre normal, sino el drama del sér excesivamente intelectualizado. ¿Qué puede importar al mundo el masoquismo mental del pensador? Estamos hartos de reglas, cánones y clasificaciones a priori. Evitemos la montaña de prejuicios que impide la acción, buscando el ágil salto de los libres, el cuerpo sano y el alma inocente que ignora el padecer de la sabiduria.

\section{Goethe}

Lo violento, lo que se produce a saltos, es contrario a la naturaleza. No hay evolución duradera donde no actúan fuerzas progresivas de transformación. Quien cultiva el desatino, se desvanece.

\section{APOLLINAIRE-MARINETTI-PICASSO}

El desatino que todos llevamos dentro, forma parte de la estética moderna. ¿Por qué sólo el raciocinio habría de regir la obra de arte? También el impulso instintivo tiene su importancia. Los clásicos descansan en el recuerdo y en la medida; nosotros en nuestro capricho. ¿Cuál más valeroso? ¿Quién busca apoyo, o quien parte sólo de sí mismo, desdeñando ayuda?

\section{Goethe}

El neófito encubre la dificultad de aprender con un falso coraje. La supuesta originalidad del vanguardismo es, en el fondo, pobreza disfrazada de exotismo.

\section{Apollinaire-Marinetti-Picasso}

Dimos vida al motor, esa nueva bestia que sirve y hostiga a la humanidad. Matamos al claro de luna con luz de reflectores que iluminan la fuerza, el vértigo, la total $\mathrm{y}$ desnựa indepen- 
dencia.: Al arte griego opusimos el arte negro: Liberamos las artes por medio del juego absoluto - caligramas, ideogramas, psicodramas, pintura abstracta, etc- Cuando nuestra artillería destapa sus botellas ardientes, el mundo renace. El jazz, que pone en circulación las cosas, es el espejo de lo actual, incoherente, velocísimo, ansioso de jolgorio y de lo nuevo.

\section{GoeThe}

¿Nuevo?. Sólo es nuevo lo que fecunda el espiritu. La vanguardia no fecunda, distrae; no es veraz, sino intrascendente $y$ pasará como la espuma en la ola, sin tiempo de fijarse en formas perdurables.

\section{A pollinatre-Marinetti-Picasso}

¿Qué importa! Bastó para batir la costumbre y la estupidez de las reglas. ¿Qué más se le puede pedir? Dió fin al absurdo de las comparaciones; desde ella no hay un arte "mejor" que otro; todo se funde en la igualdad de la expresión.

\section{GoEthe}

La jerarquía es ley natural; nadie puede prescindir de una escala de valores. Todo arte auténtico es entrañable; ¿y cómo hablar de acciones entrañables cuando se iguala lo bello con lo horrible y lo simple con lo laborioso?. Obrar es fácil; pensar difícil. El que hace mucho ruido no cristaliza. El arte está ahí para ser mirado, no para que se hable de él. ¿Soportarias la prueba? Las creaciones de vanguardia no hablan a la inteligencia racional ni a la capacidad sensoria; tal yez sólo distraen con su incoherencia y su fealdad. Los antiguos tenían grandes intenciones que llevaron a término. Los modernos tuvimos grandes. intenciones que nuestras obras rara vez reflejaron en toda su pureza y energía. Los vanguardistas carecen de grandes. y 
pequeñas intenciones, persiguiendo sólo el efecto, merced a una actividad dispersa que toca sin buscar. Nada de lo vuestro quedará en pie.

\section{Apollinaire-Marinetti-Picasso}

Es prematuro decirlo... Empero, nadie negará que abrimos rumbo a los que venían detrás.

\section{GoEthe}

Abrir un camino es enseñar una verdad; cuâl es la vuestra?

A pollinatre-Marinetti-Picasso

¡La deshumanización del arte!

\section{Goethe}

¿Es posible desespiritualizar el espiritu? Arte es interpretación, estilización de las cosas a través del sentimiento del artista. Eliminando la emoción humana, se anula todo principio natural de creación. La frialdad del objeto sólo vive por el ardor del sujeto que lo percibe y reproduce.

\section{A pollinaire-Marinetti-Picasso}

El instinto es también resorte humano...

\section{Goethe}

.. que la razón debe controlar.

\section{Apollinatre-Marinetti-Picasso}

¡Nada de controles! Es necesario prescindir de lógicas, reglas y operación preestablecida: Venga lo espontáneo, el flujo 
de lo subconsciente. En vez de Winckelmann, tirano de los cánones, bienvenido Freud, que lleva a las cavernas de la psique. Impulsos reprimidos, teoría recesal, automatismo artístico, los sueños y otras consecuencias del psicoanálisis: he ahí nuestra meta. El sér deshumanizado, completamente libre, es el arquetipo.

\section{GoETHE}

Hombre deshumanizado es paradoja.

\section{Apollinatre-Marinetti-Picasso}

Más bien la evasión del cerebralismo.

\section{GOETHE}

Teméis la disciplina.

\section{Apollinatre-Marinet't-Picasso}

La despreciamos, prefiriendo la irrupción que es su contrario.

GoETHE

Sin método no habria historia. La Afrodita de Melos no es fruto de improvisación, sino resultado de una técnica perfeccionada por los siglos. Detrás de Signorelli hay centenares de maestros primitivos. Haendel no se explica sin la polifonía medieval y el épico lirismo de Orlando di Lasso. Las grandes obras nunca viven aisladas; mas como eslabones de una cadena interminable que los artistas forjan torso contra torso. $\mathrm{El} \mathrm{hom-}$ bre es, siempre, el mejor maestro del hombre.

\section{A Pollinaire-Marinetti-Picasso}

$\therefore$ Ea tradicion de la "cátena" fué róta por nosotros. 
Goethe

Sois el eslabón mal fundido que se volatiliza.

A pollinaire-Marinetti-Picasso

Na venimos del bronce...

Gosthe

... que es eterno...

Apollinatre-Marinetti-Picasso

... sino del viento, informe y siempre diferente.

Goethe

¡Alma del hombre, cómo te pareces al agua! ¡Destino del hombre, cómo te pareces al viento!

Apollinaire-MarinetTi-Picasso

Trocad vuestro arte estático por un principio de actividad dinámica.

\section{GoETHE}

Arte dinámico es un contrasentido. Toda filosofía del arte rezuma la trágica lid del creador con las transformaciones; su adversario implacable es el Tiempo, que devuelve a las tinieblas el resplandor fugaz de la obra humana. El artista lucha con la cruel fugacidad de las cosas, la ley inmanente de las mutaciones y la destritcción final de la materia organizada por su genio. ¿Qué piensa el creador frente a su obra? " iDetente, oh bello. instante !". Es decir: fija tu forma, dí tu mensaje, alcanza tu esplendor para que los hombres se miren en tu espejo, ajenos a la fatalidad del cambio: : 


\section{Apollinaire-Marinetti-Picasso}

La raiz de lo nuevó está en el tránsito vertiginoso de las sensaciones, la multiplicación de.las imágenes, el vuelo disparado de la flecha. Una motocicleta que arranca de improviso; he ahi lo que nos consume: partir!

\section{GoEThe}

No hay más arte que aquel que vence la fatiga y se resuelve por madura serenidad. Para fijar el tránsito terrestre, es menester la pugna sostenida con el mundo y consigo mismo. No el deseo; cl esfuerzo perseverante rige la obra creadora.

\section{A POLlinaire-MarinetTt-PICASSo}

La sugestión histórica, ambiental y el casillero estorban. La dinámica del tiempo consiste en ser radiante como la luz que fluye şin trabas. ¿Cómo háblar de un arte estático, equivalente de lo corrupto y limitado? La primera condición de lo dinámico está en que no es clasificable in aetermum. En sentido social, interpreta el mundo dentro del movimiento incesante y mudable de las cosas, apartándonos del ángulo fijo para trasladarnos a la plena rotación. Asi "El Perro y la Señora en Movimiento", de Balla, es infinitamente superior al neoclasicismo de Ingres o David, encadenados al dogna anecdótico y visual.

\section{Goethe}

¿Quiën entiende a Balla?. Algunos descabellados, previo aderezo literario... Ingres, David, gustarán siempre, unas veces más, otras menos, según el gusto de las épocas; siempre al fin, porque sirs cuadros tienen verdad y belleza. Es que el arte, todo, es estático, en el temblor resonante del mármol o la dorada cavidad del verso; en el juego vivaz de los colores o el mar jimpalpable de la música; en la fluencia concertada de la prosa 0 
la petrificada armonía de los templos. Lo que se niega a pasar; lo siempre igual a si mismo; la fuerza retenida que elabora su acción en la inmovilidad; he ahí el arte.

\author{
Apollinaire-Marinetti-Picasso \\ Lo pasivo huele a estancamiento.
}

GoEthe

No hagáis sofismas. Lo estático posee dinámica interna, que actúa de hombre a hombre, de escuela a escuela, de época a época. Siempre igual a si mismo, es siempre distinto a la comprensión individual, porque vive cargado de significaciones, como la vida apretada de zumos.

Apollinaire-Marinetri-Picasso

Aceptáis nuestro principio dinámico...

\title{
GoETHE
}

El vuestro, no. Admito cierta fuerza interna que se desplaza de adentro al exterior. Pero en lengua racional el arte, cosa en si, sólo es estático: en lo físico, como equilibrio y reposo de fuerzas; en lo espiritual, como inmersión del alma que se arroba en la cosa contemplada para participar de su belleza.

\section{A POLlinaire-Márinetti-Picasso}

Creamos sin ideas preconcebidas, no somos esclavos de la imaginación. Lo estático mata la vida.

\section{Goethe}

El artista es inquieto; mas su obra se inmoviliza en el espacio. Penetrad en su :terrible densidacl el drama del artista; ¿qué, 4 
pasa? Es una pugna eterna entre la marcha inexorable de las cosas y el anhelo de organizar el mundo quieto de la creación intelectual.

\section{Apollinatre-Marinetti-Picasso}

Aportando lo espontáneo contra la ceñida rigidez del clásico, hemos innovado.

\section{Goethe}

Sois una pausa en el camino del arte. ¿Hasta qué punto eficaz? Es prematuro decirlo. Aguardaremos la hora de vuestro redescubrimiento.

\section{Apollinaire-Marinetti-PicAsso}

¡El futuro nos pertenece! Somos los más nuevos.

\section{Goethe}

Olvidáis que los griegos, siendo los últimos, son siempre los primeros.

\section{Apollinaire-Marinetti-PiCASso}

¡Los griegos, bah! ¿ Por qué negar la poderosa vitalidad del modernismo?

\section{Goethe.}

Porque el orden no. admite el desorden. Mi tiempo fué un fin; el vuestro es un comienzo. ¿Cómo entendernos?

\section{Apothinaire-MarinetTi-PiCAsso}

Vivimos próximos al niño, o sea la naturalidad. Vos, an- ciano, representäis el insoportable peso de lo estatuido 
GoETHE

El clásico pertenece a un orden cerrado y el vanguardista a un orden abierto. Creéis actuar en un paisaje sin horizontes, que se prolonga hasta el infinito, cuando en verdad conduce al vacío. El clásico sabe que sólo se marcha al infinito, recorriendo lo finito en todas direcciones.

\section{A pollinaire-Marinetti-Picasso}

Nosotros inauguramos una época. El disparate puro, los "ismos", la representación automática de las cosas. Cada día, cada hora, sorpresas.

\section{GOETHE}

Sois la señal disolvente. Para abrir una época hacen falta dos cosas: una gran cabeza y una buena herencia; aun teniendo aquélla os falta ésta. El arte paleolítico, la cueva de Altamira, los dibujos rupestres; hoy mismo, las incoherencias de niños y dementes sobre el papel; he ahi vuestro espejo.

\section{Apollinaire-Marinet'ri-Picasso}

Por nosotros descansa la inteligencia de la sabiduria.

\section{Goethe}

La sabiduría es el aire que respira la inteligencia:

\section{A pollinaire-Makinetti-PiCasso}

Somos el impulso rebelde; vos la conformidad. ¿Aguilas y tortugas?

GOETHE

$\therefore \quad$ La tortuga devora los años; el águila se pierde en el vacío. 
Pertenecéis a un tiempo de expulsión; yo vengo de otro de absorción.

\section{A POLLINAIRE-MARINETTI-PICASSO}

Casi dais la clave...

\section{Goethe}

La personalidad propia nos impide comprender la ajena. Acabo de eliminar la mía para acercarme a vosotros.

A pollinaire-Marinetti-Picasso

La ruptura con el pasado; he aquí nuestro drama...

\section{Goethe}

La afirmación de lo que fué; he ahí el mío...

\section{Apollinaire-MarinetTI-PICASSo}

Egipto es el estatísmo de la línea. Grecia, la línea en movimiento. El gótico la verticaliza hacia los cielos: El Renacimiento la tiende sobre la tierra. A nosotros nos tocó descomponerla. Somos la evasión. Cada época tiene su estética propia. No podemos desviarnos. Acaso descomponer no sea un juego... Dislocamos las formas como el vértigo de la velocidad nos destruye y nos recompone a cada instante. Tal vez un clásico apunta en la porfía. Renegamos de la ciencia para volver a la naturaleza. ¿Qué somos? Un retorno. ¿Qué dejaremos? El equilibrio. Los viejos no pueden entendernos; las generaciones mozas, sí. La estética moderna tiende a crear unidad armónica entre arquitectura, vestido, vehículo, plástica, letras, etc. Así nacen la casa funcional, la línea aerodinámica del avión y el automóvil, el traje recto y sobrio, la escultura sintética, la pintura abs-

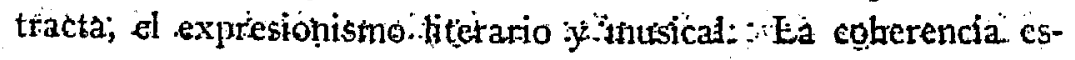


tilística de nuestro tiempo nace con la revolución plástica, pero su significado alcanza a todos los elementos de la vida humana. Busca la simplicidad, el funcionalismo de la línea, la síntesis expresiva; todo lo cual corresponde a la necesidad de evolución espiritual del hombre. Cuando éste tuvo necesidad de hacer andar a las cosas inanimadas, y aunque no conocía otro medio de locomoción que las piernas, no pensó en crear piernas más largas, sino en una cosa bien distinta y casi extraña; inventó la rueda. Hay que salir de la tradición para volver a inventar la rueda. Pero como nosotros no llegaremos tan lejos y otros aprovecharán lo que iniciamos, sólo nos queda atropellar. ¡ ¡Fuera límites y trabas! Con precipitación y fuego labremos el presente.

\section{GoEThE}

Buscad la proporción; amad el límite; refrenad impulsos. Por lejos que alcancéis, nunca os dañará la disciplina. A la hora de reanudar el conflicto inacabable de lo romántico y lo clásico, de lo nuevo con lo antiguo, intervenid con vuestra fe y vuestra experiencia, sin olvidar que sólo se oye en la disputa de los siglos, la voz de aquél que decir puede: avancé sin pausa y sin prisa como la estrella.

Fernando Díez de Medina. 
